\title{
Measuring Anxiety in Youth with Learning Disabilities: Reliability and Validity of the Multidimensional Anxiety Scale for Children (MASC)
}

\author{
Nicholas S. Thaler • Ellie Kazemi · Jeffrey J. Wood
}

Published online: 20 April 2010

(C) The Author(s) 2010. This article is published with open access at Springerlink.com

\begin{abstract}
Youth with learning disabilities (LD) are at an increased risk for anxiety disorders and valid measures of anxiety are necessary for assessing this population. We investigated the psychometric properties of the Multidimensional Anxiety Scale for Children (MASC; March in Multidimensional anxiety scale for children. Multi-Health Systems, North Tonawanda, 1998) in 41 adolescents (ages 11- 17 years) with LD. Youth and parents completed the MASC and were administered the semi-structured Anxiety Disorders Interview Schedule: Child and Parent Versions (ADIS: C/P; Silverman and Albano in The Anxiety Disorders Interview Schedule for DSM-IV-Child and Parent Versions. Psychological Corporation, San Antonio, 1996). Results found that child and parent reports of Social Anxiety on the MASC closely corresponded with ADIS-generated social phobia diagnoses, and parent total scores discriminated well among youth with and without any anxiety disorder. A multi-method multi-trait matrix provided evidence of the construct validity of the MASC total score for both parent and child reports. Our findings provide empirical evidence that parent and child versions of the MASC are useful for assessing anxiety in youth with LD.
\end{abstract}

Keywords MASC $\cdot$ Learning disabilities · Child anxiety $\cdot$ Parent-child agreement · Multi-trait multi-method matrix

While anxiety disorders in normative samples of school-aged children are considered widespread with prevalence rates ranging between 10 and $21 \%$ [3, 4], research indicates

\footnotetext{
N. S. Thaler ( $₫)$

Neuropsychology Research Program, Department of Psychology, University of Nevada Las Vegas, 4505 Maryland Parkway, Las Vegas, NV 89154-5030, USA

e-mail: nthaler82@aim.com

E. Kazemi

Department of Psychology, California State University, Northridge, CA, USA

J. J. Wood

Graduate School of Education and Information Studies, University of California, Los Angeles, CA, USA
} 
that youth with learning disabilities (LD) may experience even higher levels of anxiety [5-10]. This is an issue, as emotional stability and lower stress predict future success in youth with LD [11]. To consider the overall well-being of this population, an appropriate diagnostic measure that can accurately detect anxious comorbidity is needed. At present, accurate detection of anxiety in the LD population is hampered by the lack of brief, reliable, and sensitive assessment tools that are validated for use with youth with LD. Therefore, the purpose of the present study was to examine the psychometric properties of the Multidimensional Anxiety Scale for Children [1] in a sample of children and adolescents with LD.

According to the most recent Annual Report to Congress on the Implementation of Individuals with Disabilities Education Act, over $4 \%$ percent of the general population between the ages of 6 and 21 receive special education services for a specific LD. Youth with LD comprise $47.4 \%$ of students in special education [12] and exhibit significant discrepancies between their intellectual abilities and their academic achievements which often results in poor functioning in academic environments [13]. Additionally, youth with LD can have difficulties making and maintaining friendships with same-age peers $[14,15]$. The academic and social stresses that these youth face are so high that an estimated $30-40 \%$ of students with LD drop out of high school each year [16]. As youth with LD experience increased stress in social and academic environments, it is not surprising that the co-occurrence of anxiety disorders with LD becomes even more debilitating and a major mental health concern [11]. However, despite the high comorbidity of anxiety disorders among youth with LD and their negative effects on psychosocial development, most of these children and adolescents are left untreated for their anxiety [17].

The standardized academic and intelligence tests given to students who are considered for special education placement often fail to discriminate symptomology associated with LD from those associated with anxiety. As a result, the general tendency among school professionals is to diagnose youth who are academically performing at below grade-level with a primary diagnosis of LD and rule-out emotional disturbance as a possible contributing factor to the learning difficulties [18]. However, it is important that additional methods of evaluation are available to assist in accurately identifying sources of academic and social problems in their students, such as excess anxiety that may accompany a learning disability.

A few different factors may account for the neglect of treating anxiety symptoms in youth with LD. As the diagnostic label assigned to a client determines the types of intervention provided, emotional disorders are often underdiagnosed in LD populations [19]. This may be because the federal definition of LD is exclusionary in nature and specifies that the term LD does not apply to children who have learning problems that are primarily caused by emotional disturbance [20]. In many cases, it is unclear if learning difficulties are primarily the result of a learning disability (i.e., a disorder of basic cognitive processes), anxiety (which is known to also affect learning processes), or the co-occurrence of both disorders. Another explanation for underdiagnosing anxiety disorders in youth with LD is that the anxiety symptoms are often missed due to diagnostic overshadowing [21]. Children and adolescents with LD often have a limited vocabulary, slower processing speeds, deficiencies in memory and communication, and may have difficulties reading social cues and avoid novel social situations [22, 23]. They may feel embarrassed when called upon to read out loud, answer questions in class, express their needs, or participate in other academic activities. These students may worry excessively about their performances or successes while also experience a lack of control over their academic and social 
outcomes. These symptoms might erroneously be viewed as part of the primary diagnosis of $\mathrm{LD}$, overshadowing the presence of co-occurring anxiety.

To resolve some of these issues and to accurately discriminate and assess anxiety disorders among youth with LD, psychometrically validating screening tools are necessary. The MASC is one noteworthy measure and is currently one of the most widely used measures in clinical trials among youth populations with anxiety disorders. This measure has proven to have excellent convergent validity with the Revised Children's Manifest Anxiety Scale [24] and divergent validity with the Children's Depression inventory [25], establishing it as a high-quality self-report measure of anxiety [26, 27]. Additional studies have found that the MASC has a four-factor structure with strong internal reliability [28, 29], it is appropriate for identifying anxiety in ADHD populations [30], it is applicable in other cultures [31-33].

A study by Wood and colleagues [34] established the MASC's convergent validity with the Anxiety Disorders Interview Schedule: Child and Parent Versions (ADIS: C/P; [2]) for the Diagnostic and Statistical Manual of Mental Disorders, 4th edition (DSM-IV; [35]). Results showed that the MASC accurately predicted elevated levels of social phobia, separation anxiety disorder, and panic disorder with the ADIS, though it fell short on measurements of generalized anxiety disorder. As the ADIS is considered to be the gold standard assessment tool for diagnosing anxiety [36], these results supported the MASC's utility as a measure that can aid in the detection of anxiety disorders.

As such, the MASC may be a potentially useful instrument for youth with LD, though no research has yet been conducted on its reliability and validity in this population. Although there is evidence that the three main types of LD (reading, mathematics, written expression) along with other subtypes (e.g., nonverbal) have some differential cognitive dysfunction [37, 38], they share a common risk factor for stress and anxiety (i.e., academic underperformance), have high comorbidity rates with each other, and have been associated with similar emotional and behavioral disturbances [39, 40]. Further, given the MASC's relative brevity and simplicity, it is easy to administer the MASC in a way that avoids reading comprehension problems often associated with LD (e.g., reading test items out loud to the youth while they follow along and answer privately on their own form). Therefore, the objective of our study was to examine the MASC's psychometric properties in a heterogeneous sample of youth with learning disabilities by evaluating its internal consistency, parent-child agreement, convergent/divergent validity, and correspondence with ADIS-generated anxiety diagnoses. We aimed to establish whether or not the MASC is an appropriate tool to apply to a general population of youth with LD.

\section{Method}

\section{Participants}

Participants were 42 children in middle (64.3\%) or high school (57.1\% public school) who had a prior diagnosis of LD as demonstrated by a school Individual Education Plan or a previous psychological report. The second author used the IQ-achievement discrepancy criterion and confirmed LD diagnoses. Participants were mostly boys (78.6\%) and within the age range of 11 and $17(M=13.75, \mathrm{SD}=1.81)$. Participants were typically diagnosed with LD within the past five years $(M=5.00, \mathrm{SD}=2.77)$. Overall GPAs were in the 2.0 range $(M=2.53, \mathrm{SD}=.68)$. Each student had one parent who participated in this study following parental consent and youth assent. The majority of parent participants were 
mothers $(83.3 \%)$ and half $(50.0 \%)$ were married. According to participants' self-reports, there were $58.7 \%$ Caucasian, $16.7 \%$ African American, 9.5\% Hispanic, 2.4\% Middle Eastern, and $7.1 \%$ participants of other races and ethnicities. Nearly all $(97.6 \%)$ of the students were born in the U.S. and spoke English (95.1\%) as a first language. Seven of the youth $(16.7 \%)$ were adopted or in foster placement.

\section{Measures}

The Multidimensional Anxiety Scale for Children (MASC-C; [1]) is a standardized, 39 item self-report measure of anxiety. Each item for is rated on a 4-point Likert scale ranging from 0 (never true) to 3 (often true). The four empirically derived factor index scores are Social Anxiety, Separation Anxiety, Harm Avoidance, and Physical Symptoms. The MASC also has a total score. March and colleagues [1] reported Cronbach's alphas ranging from .74 to .85 on the child version while Wood et al. [34] reported Cronbach's alphas ranging from .64 to .82 on the child and parent versions respectively. These coefficients were comparable to our internal consistency ratings from .70 to .83 for the MASC-C and from .57 to .83 for the MASC-P.

The MASC has a standardized child version [1] and a research-based parent version [33], with items that are essentially identical. The wording is altered so that the child reports his or her own symptoms, while the parents report their child's symptoms, but the content is the same. Parent-child agreement on the MASC has been modest to moderate [34] and comparable to other anxiety measures [28], with agreement diverging when clinical symptoms are more severe [41]. However, in other areas of convergent validity the MASC has proven to be more promising, such as MASC-ADIS agreement [34].

The Anxiety Disorders Interview Schedule: Child and Parent Versions (ADIS: C/P; [2]) was administered to evaluate the presence of co-occurring anxiety disorders in the participants. This measure is a semi-structured interview that provides reliable diagnoses of anxiety disorders that match the DSM-IV. Silverman et al. [42] reported kappa coefficients in the excellent range (.80-.92) for combined parent-child diagnoses, interclass coefficients in the excellent range (.78-.99) for child interview, and in the good to excellent range (.52-.94) for the parent interview.

Along with the MASC and the ADIS, we used two other frequently utilized measures in research with students with learning disabilities. The Piers-Harris Children's Self-Concept Scale-2nd edition (PH-2; [43]) is a self-report form that was normed on 1,387 children and adolescents (boys $=689$; girls $=698$ ) between the ages of 7-18 throughout the United States. The alpha reliability coefficient for the PH Children's Self-Concept Scale ranges from .88 to .93 . This measure of self-concept has been frequently used in research with students with learning disabilities [44, 45]. For the present study, the PH2 Behavioral Adjustment Index (BAI) was selected as a measure of divergent validity. Cronbach's alpha of this scale in our sample was .62.

In addition, Achenbach checklists were given to the parents (Child Behavior ChecklistParent [CBCL-P]; [46]) and teachers (Teacher Report Form [TRF]; [46]). The broad Internalizing and Externalizing scales were selected as measures of convergent and divergent validity respectively. The Internalizing scale is composed of items from the Withdrawn, Somatic Complaints, and Anxious/Depressed scales and the Externalizing scale is composed of items from the Delinquent and Aggressive Behaviors scales. Cronbach's alpha for the CBCL Internalizing scale was .91 and for the Externalizing scale was .85. Cronbach's alpha for the TRF Internalizing scale was .85 and for the Externalizing scale was .94 . 
Procedure

To maximize efforts to recruit ethnically diverse participants we used UCLA Office for Protection of Research Projects Institution Review Board (IRB) approved letters and flyers printed in English and Spanish. The second author recruited bilingual research assistants who used IRB approved scripts for participant recruitment and helped with translation during assessment. The research assistants advertized the study using phone scripts, online forums and websites, and personal visits at various public and non-public schools, tutoring and disability centers, parent associations and advocacy centers located in the inner cities and diverse communities.

Inclusion criteria were that the child must have been in middle or high school and had prior classification of LD as demonstrated by school Individual Education Plan or previous psychological reports. Potential participants were screened over the telephone and if eligible, a 3-h appointment was made with the parent. Interviews were conducted in private designated rooms at UCLA after parent consent and child assent were obtained. All selfreport questionnaires were read out loud to the child by a trained research assistant to minimize differences between respondents based on reading ability. Parents were also accompanied by a research assistant during the entire assessment and they were assisted if they had any questions on the measures. The second author, blind to scores on all other measures, conducted all ADIS child and parent interviews and recorded the scores. All self-report data and checklists were monitored by IRB certified undergraduate research assistants affiliated with the study, trained and supervised by second author.

\section{Data Analysis}

All participants were evaluated for LD and comorbid anxiety diagnoses during the interviews and assessments. LD and anxiety disorders were diagnosed according to DSM-IV diagnostic criteria based on psychological evaluation, interviews (including the ADIS-IV), and behavioral assessment. Given our small sample size, a power analysis was conducted to ensure that further comparative analyses would be appropriate. We then assessed for the MASC's interrater reliability, construct validity, and criterion validity for anxiety disorders using partial correlations, a multi-trait multi-method matrix, and receiver operating characteristic curves.

\section{Results}

\section{Clinical Findings}

After undergoing evaluation, 41 of our participants (1 was omitted due to missing data) were diagnosed with the following learning disabilities: $2(4.8 \%)$ had a reading disability only, $4(9.6 \%)$ had a writing disability only, $2(4.8 \%)$ had a mathematics disability only, 8 $(19.5 \%)$ had a reading and writing disability, $2(4.8 \%)$ had a reading and mathematics disability, $1(2.4 \%)$ had a writing and mathematics disability, $6(14.7 \%)$ had a reading, writing, and mathematics disability, and 16 (39.0\%) had a learning disorder not otherwise specified (e.g., nonverbal learning disability). With regard to anxiety disorders, $4(9.8 \%)$ were diagnosed with separation anxiety disorder (SAD), 1 (2.4\%) was diagnosed with social phobia (SP), and $5(12.2 \%)$ were diagnosed with generalized anxiety disorder (GAD), 2 (4.8\%) were diagnosed with SAD and SP, 2 (4.8\%) were diagnosed with SAD 
and GAD, 2 (4.8\%) were diagnosed with SP and GAD, and 1 (2.4\%) was diagnosed with all three disorders. Twenty-four youth $(58.5 \%)$ were not diagnosed with any anxiety disorder. Comorbid diagnoses were as follows: $4(9.8 \%)$ of the children were diagnosed with dysthymic disorder, 33 (80.5\%) were diagnosed with ADD or ADHD, 3 (7.3\%) were diagnosed with oppositional defiant disorder, 1 (2.4\%) was diagnosed with conduct disorder, and $4(9.8 \%)$ were diagnosed with a mood disorder not otherwise specified.

Power Analysis

There is $80 \%$ power to detect an $r$ coefficient of .41 at $p<.05$, two-tailed, for a sample of 41 youth. The median mother-child agreement correlation for MASC scales published in the test manual ([1]; p. 56) was .45; hence, a sample of 41 should confer about $80 \%$ power to detect this magnitude of effect. With regard to diagnostic comparison analyses, the March ([1]; p. 54) test manual provides proportions of false positive to true positive anxiety diagnoses based on MASC scores. Based on these proportions, there is $80 \%$ power to detect a group difference at $p<.05$, two-tailed, at $N=21$ (16 non-diagnosed youth and 5 diagnosed youth). Thus, the study was adequately powered for the planned analyses.

Preliminary Analysis

Means, standard deviations, and ranges for all study variables are presented in Table 1.

Table 1 Means, standard deviations, and ranges of study variables

\begin{tabular}{|c|c|c|c|}
\hline & Mean & SD & Range \\
\hline \multicolumn{4}{|l|}{ MASC-C } \\
\hline Physical symptoms & 46.31 & 8.3 & 35.0 \\
\hline Harm avoidance & 45.19 & 12.9 & 50.0 \\
\hline Social anxiety & 49.98 & 10.1 & 46.0 \\
\hline Separation/panic & 53.64 & 12.6 & 50.0 \\
\hline Total score & 47.79 & 11.0 & 43.0 \\
\hline \multicolumn{4}{|l|}{ MASC-P } \\
\hline Physical symptoms & 46.63 & 9.0 & 39.0 \\
\hline Harm avoidance & 52.98 & 10.7 & 64.0 \\
\hline Social anxiety & 60.93 & 10.4 & 43.0 \\
\hline Separation/panic & 59.70 & 12.5 & 40.0 \\
\hline Total score & 56.48 & 9.9 & 42.0 \\
\hline \multicolumn{4}{|l|}{ ADIS-IV } \\
\hline CSR anxiety & 2.56 & 2.4 & 6.0 \\
\hline CSR behavioral & 4.39 & 2.1 & 6.0 \\
\hline \multicolumn{4}{|l|}{ CBCL } \\
\hline Internalizing & 58.76 & 12.2 & 46.0 \\
\hline Externalizing & 53.83 & 9.3 & 40.0 \\
\hline \multicolumn{4}{|l|}{ TRF } \\
\hline Internalizing & 52.69 & 8.0 & 29.0 \\
\hline Externalizing & 53.96 & 9.5 & 37.0 \\
\hline
\end{tabular}


Children's age did not significantly correlate with MASC-C scores, $r(41)=-.10$, $p>.05$. Additionally, a series of ANOVAs confirmed there were no significant differences on the MASC-C due to gender, $F(1,40)=.12, p>.05$, ethnicity, $F(4,37)=.73, p>.05$, or a diagnosis of ADHD, $F(1,40)=2.56, p>.05$. ANOVAs also confirmed no significant differences on the MASC-P due to gender, $F(1,38)=2.6, p>.05$, ethnicity, $F(4,35)=$ $1.5, p>.05$, or a diagnosis of ADHD, $F(1,38)=.40, p>.05$. However, children who were identified with LD by school districts reported significantly lower anxiety on the MASC-C than children who were identified through private psychologists or clinics, $F(1,40)=4.32, p<.05$.

\section{Parent-Child Agreement}

Parent-child agreement was assessed via partial correlations between the MASC-C and MASC-P scales, controlling for LD identification source to assess interrater reliability. Interrater correlation coeffecients were as follows: Physical Symptoms, .24; Harm Avoidance, .10; Social Anxiety, .48; Separation/Panic, .19; MASC total, .32. The correlations for the Social Anxiety factor and the overall total score were statistically significant $(p<.05)$. The intraclass correlation coefficients (average measures, random effects model) for parent-child agreement on the MASC indexes were as follows: Physical Symptoms, .36; Harm Avoidance, .06; Social Anxiety, .66; Separation/Panic, .30; MASC total, .51.

\section{Construct Validity}

We used a multi-trait multi-method matrix (MTMM; [47]) approach to evaluate MASC construct validity in our sample. Convergent and divergent validity of the MASC-C and -P total scaled scores was evaluated with the Piers-Harris II Behavioral Adjustment Index (BAI), the CBCL Internalizing and Externalizing indexes, the TRF Internalizing and Externalizing indexes, and ADIS-IV clinical severity ratings (CSR) of anxiety disorders and disruptive behavior disorders. As the ADIS-IV provides separate CSRs for social phobia, separation anxiety, and generalized anxiety disorder, we took the highest CSR of any of these three disorders as the overall ADIS anxiety score. The highest CSR among ADHD (excluding ADHD-Primarily Inattentive), conduct disorder, and oppositional defiant disorder served as the ADIS behavior disorder score.

Convergent validity is identified through the degree of correspondence of similar traits across different assessment modalities/informants, while divergent validity is identified as the relative independence of different traits across the same and different assessment modalities/informants. For this study, traits (i.e., anxiety) that converge across four discrete measures (i.e., MASC-C, MASC-P, CBCL-Internalizing, ADIS-IV Anxiety CSR) are monotrait-heteromethod correlations and should have larger coefficients than heterotraitheteromethod correlations. When different traits diverge from one another in both heterotrait-monomethod and heterotrait-heteromethod correlations, they support divergent validity. We used Cohen's parameters of effect size strength [48] to classify our correlations. In our matrix (see Table 2), the MASC-C total score had medium to large effect sizes with monotrait-heteromethod measures such as the MASC-P (.35), CBCL Internalizing index (.24), the TRF Internalizing index (.28), and the CSR anxiety score (.40). In comparison, heterotrait correlations with the Piers-Harris BAI (.07), the CBCL Externalizing index (-.17), the TRF Externalizing index (-.04), and the CSR behavior disorder scores $(-.17)$, all had trivial ES or were negative. 
Table 2 Means and standard deviations of MASC-C and MASC-P scores for youth with and without ADIS anxiety disorders

\begin{tabular}{lll}
\hline Diagnosis & $M$ (Social anxiety factor) & SD (Social anxiety factor) \\
\hline MASC-C & & 12.6 \\
Social phobia Dx $(n=6)$ & 62.80 & 7.7 \\
No social phobia Dx $(n=36)$ & 47.64 & 7.6 \\
MASC-P & & 10.0 \\
Social phobia Dx $(n=6)$ & 70.60 & SD (Separation factor) \\
No social phobia Dx $(n=35)$ & 59.81 & \\
& $M$ (Separation factor) & 15.1 \\
\hline MASC-C & & 10.8 \\
Separation anxiety Dx $(n=9)$ & 58.83 & 11.4 \\
No separation anxiety Dx $(n=33)$ & 51.75 & 12.5 \\
MASC-P & & SD (Total score) \\
Separation anxiety Dx $(n=9)$ & 63.67 & 11.8 \\
No separation anxiety Dx $(n=32)$ & 59.00 & 9.6 \\
\hline & $M$ (Total score) & 8.7 \\
\hline MASC-C & & 9.0 \\
SoP, SAD, or GAD Dx $(n=16)$ & 51.29 & \\
No SoP, SAD, or GAD Dx $(n=26)$ & 45.21 & \\
MASC-P & 62.67 & 54.33 \\
SoP, SAD, or GAD Dx $(n=16)$ & & \\
No SoP, SAD, or GAD Dx $(n=25)$ & & \\
\hline
\end{tabular}

The MASC-P total score had the same correlation coefficient with the MASC-C and the Piers-Harris BAI (.35). The MASC-P total score had medium to large effect sizes and positive correlations with the TRF Internalizing index (.35) and the CSR anxiety scores (.40) compared with corresponding heterotrait-heteromethod correlations, namely, the TRF Externalizing index (-.36) and the CSR behavior disorder score (-.09). Hence, this pattern of findings largely convergent and divergent validity of the MASC-C and -P in this sample.

\section{Exploratory Criterion Validity Analysis}

We ran a series of ANCOVAs comparing the mean MASC-C and MASC-P factor scores of children who met the criteria for a diagnosis with those who did not, with source of the LD diagnosis serving as the covariate. The Separation/Panic index was used as the DV for separation anxiety disorder, the Social Anxiety index was the DV for social phobia, and the MASC total score was the DV for any anxiety disorder (vs. none). In addition, we ran receiver operating characteristic (ROC) curve analyses to determine the optimal cutoff score for a diagnosis. We used raw MASC scores to be consistent with Wood and co-authors' study [34]. As some of our clinical groups (e.g., separation anxiety group) had small sample sizes, the following criterion validity analyses are considered exploratory, although some significant findings were noted. 


\section{Social Phobia}

The ANCOVA between MASC-C Social Anxiety factor scores of children diagnosed with social phobia and MASC-C Social Anxiety factor scores of children who were not diagnosed with social phobia was statistically significant, $F(1,37)=13.92, p<.01$. The ANCOVA comparing groups on MASC-P scores was also significant, $F(1,35)=4.89$, $p<.05$. The ROC analysis indicated that the best raw cutoff score for the MASC-C was 14 (sensitivity, .83; specificity, .92), which was comparable to Wood et al.'s [34] suggested raw cutoff score of 13.5. Area under the curve (AUC) was .89, which is considered to be an excellent classification rate [49]. For the MASC-P, the best raw cutoff score was determined to be 17 (sensitivity, .83; specificity, .65), which was again comparable to Wood et al.'s suggested score of 16.5. AUC for the MASC-P was .75. Means and standard deviations for the MASC-C and MASC-P are presented in Table 3.

\section{Separation Anxiety Disorder}

The ANCOVA for the MASC-C Separation/Panic scores that compared children with separation anxiety disorder with children without separation anxiety disorder was not significant, $F(1,37)=2.05, p>.05$. The ANCOVA for the MASC-P scores was also not significant, $F(1,36)=.69, p>.05$. The ROC analysis indicated that the MASC detected separation anxiety disorder at a rate no greater than chance $(\mathrm{AUC}=.50)$.

\section{Any Anxiety Disorder}

The ANCOVA for the MASC-C total scores that compared children with any of the three clinical anxiety disorders to children with no anxiety disorders was not significant, $F(1,37)=3.01, p>.05$. However, the ANCOVA for the MASC-P scores was significant, $F(1,35)=6.65, p<.05$. The ROC analysis indicated that a raw score of 48 was the best cutoff point (sensitivity, .86; specificity, .69), with an AUC of .75. Means and standard deviations are presented in Table 3.

\section{Discussion}

This study is the first to investigate the psychometric properties of the MASC in youth with LD. These preliminary results suggest that the MASC may be a useful tool for assessing certain traits of anxiety in youth with LD, although, as with all self-report measures, it is limited in its diagnostic capabilities. The Social Anxiety index showed the greatest sensitivity to an ADIS anxiety disorder diagnosis, with an excellent classification rate of social phobia for both the MASC-C and MASC-P and scores that differentiated youth with LD and social phobia from youth with LD alone. In addition, the MASC-P total scores were significantly higher in students with at least one of the three anxiety disorders compared to those with none. Other indexes and MASC-C total scores did not significantly differentiate LD youth with anxiety disorders, although the MASC-C did have moderate specificity in classifying separation anxiety disorder (SAD) with the Separation/Panic index. In addition, internal consistencies for both the MASC-C and MASC-P matched those found in March's standardization sample [1].

The MTMM supported construct validity with consistently higher correlations of monotrait-heteromethod measures compared to heterotrait-heteromethod measures. In 


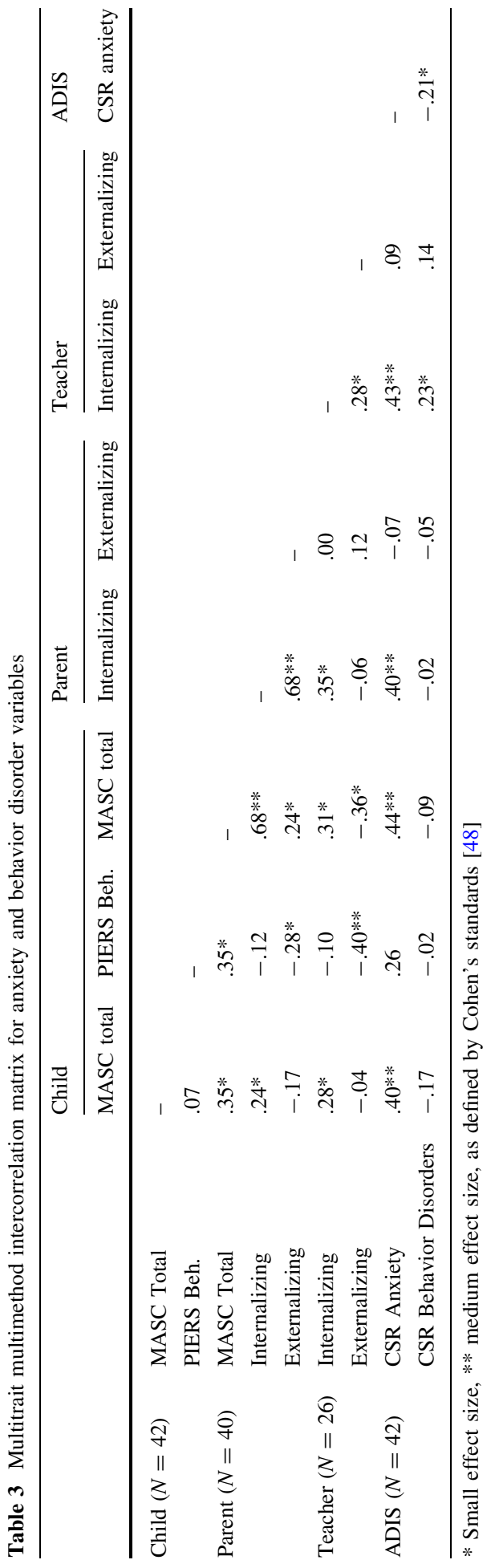


nearly all cases, monotrait-heteromethod comparisons of anxiety yielded positive correlations, while heterotrait-heteromethod comparisons had correlations around zero. The only correlations that did not match theory were the equal coefficients between the MASCP total with the MASC-C total and with the Piers-Harris BAI. However, it is possible that the children who scored higher levels of behavioral maladjustment might have been rated by their parents as experiencing higher anxiety. The ADIS-IV CSR anxiety scores had the highest correlation coefficients with the MASC-C and MASC-P scores of any other heteromethod measure, illustrating especially close convergence with a diagnostic measure administered by an independent evaluator. Overall, these findings provide some of the first evidence that the MASC is a sufficiently reliable and valid measure of anxiety in youth with LD.

As expected, parent-child concordance was modest, with strongest agreement on the Social Anxiety index and the total Score. The MASC-C and P factor and total scores had correlation coefficients ranging from .19 to .48 with the exception of the Harm Avoidance scale (which has not been empirically linked with a particular anxiety disorder in previous research; [34]), converging at about the same level as child-parent agreement on psychological symptoms in many other studies [41, 50].

The MASC has shown a particular strength in identifying social anxiety symptoms and agreement with DSM-IV diagnosis of social phobia. Children who are socially withdrawn are at risk for emotional and behavioral problems including depressive symptoms and difficulties with peers and in school [51]. Youth with LD who exhibit anxious behavior in the classroom may act so due to either academic difficulties attributed to their LD or due to genuine social anxiety. The MASC appears to be a useful tool in differentiating the source of the anxious behavior in settings where academic difficulties and social anxiety disorders may produce similar overt behaviors in youth with LD. However, the MASC did not significantly differentiate youth with LD with and without separation anxiety disorder, nor did MASC-C total scores significantly differentiate youth with LD with and without any anxiety disorder. It is possible these differences were not detected due to small sample size, though this was not an issue for the Social Anxiety factor.

Youth who were diagnosed with LD by schools had lower anxiety scores than youth who were diagnosed by private practitioners and clinics in our sample. Since private practitioners and clinics typically begin with parent referral whereas school districts begin with teacher referrals, differences between these two groups may be that parents are more likely to seek help for their children if there is concurrent emotional disturbance in addition to learning problems. It is also possible that the teachers do not refer students with overt anxiety for assessment of learning disabilities, but rather refer for emotional problems, as misdiagnosis in the school special education system has been well documented [52].

Some limitations should be addressed. Our small sample size may have underpowered some of the AUC analyses, particular with the Separation/Panic scale. In addition, we did not differentiate LD subtype in our sample. However, the reported sample of most research studies on concurrent emotional/behavioral disturbances were school identified youth with LD [39, 40, 53], though research may benefit from comparing LD subtypes to see if and how they affect MASC scores. Additional studies may also provide more information about the MASC's criterion validity by using a larger sample using and including a rigorous comparison group (e.g., matched control cases). 


\section{Summary}

This study examined the psychometric properties of the MASC in a sample of LD children. Results suggest that the MASC provides relevant information on a broad range of anxious symptoms across four factors that can better inform clinicians about the nature of anxiety in youth with LD. The MTMM provides strong evidence for the MASC's construct validity within this population. Preliminary criterion validity analysis using signal-detection theory suggests that the MASC is a valid measure for assessing youth with LD and there is little overlap between this measure of anxiety and measures of behavioral disorders such as ADHD and conduct disorder. Given our small sample size, the findings regarding the Social Anxiety factor are particularly in favor of the MASC's sensitivity to this form of anxiety, even when accompanied by an LD diagnosis. Overall, the MASC appears to be an appropriate anxiety assessment tool for youth with LD.

Acknowledgments The authors thank Erik N. Ringdahl for his insightful comments in preparing this manuscript.

Open Access This article is distributed under the terms of the Creative Commons Attribution Noncommercial License which permits any noncommercial use, distribution, and reproduction in any medium, provided the original author(s) and source are credited.

\section{References}

1. March JS (1998) Multidimensional anxiety scale for children. Multi-Health Systems, North Tonawanda

2. Silverman WK, Albano AM (1996) The anxiety disorders interview schedule for DSM-IV-child and parent versions. Psychological Corporation, San Antonio

3. Costello JE, Mastillo S, Erkanli A, Keeler G, Angold A (2003) Prevalence and development of psychiatric disorders in childhood and adolescence. Arch Gen Psychiatry 60:837-844

4. Albano AM, Chorpita BF, Barlow DH (2003) Childhood anxiety disorders. In: Mash EJ, Barkley RA (eds) Child psychopathology. Guilford Press, New York, pp 279-329

5. Al-Yagon M, Mikulincer M (2004) Socioemotional and academic adjustment among children with learning disorders: the meditational role of attachment-based factors. J Spec Educ 38(2):111-123

6. Greenham SL (1999) Learning disabilities and psychosocial adjustment: a critical review. Child Neuropsychol 5(3):171-196

7. Hoy C, Gregg N, Wisenbaker J, Manglitz E, King M, Moreland C (1997) Depression and anxiety in two groups of adults with learning disabilities. Learn Disabil Q 20(4):280-291

8. Rodriguez CM, Routh DK (1989) Depression, anxiety, and attributional style in learning-disabled and non-learning-disabled children. J Clin Child Adolesc Psychol 18(4):299-304

9. Cantwell DP, Baker L (1987) The prevalence of anxiety in children with communication disorders. J Anxiety Disord 1(3):239-248

10. Bryan JH, Sonnefeld LJ, Grabowski B (1983) The relationship between fear of failure and learning disabilities. Learn Disabil Q 6(2):217-222

11. Raskind MH, Goldberg RJ, Higgins EL, Herman KL (1999) Patterns of change and predictors of success in individuals with learning disabilities: results from a twenty-year longitudinal study. Learn Disabil Res Pract 14(1):35-49

12. U.S. Department of Education (2005) Twenty-seventh annual report to Congress on the implementation of the Individuals with Disabilities Education Act. U.S. Department of Education, Washington DC

13. McKinney JD, Osborne SS, Schulte AC (1993) Academic consequences of learning disability: longitudinal prediction of outcomes at 11 years of age. Learn Disabil Res Pract 8(1):19-27

14. Kavale KA, Forness SR (1996) Social skill deficits and learning disabilities: a meta-analysis. J Learn Disabil 29:226-237

15. Baumeister AL, Storch EA, Geffken GR (2008) Peer victimization in children with learning disabilities. Child Adolesc Social Work J 25(1):11-23 
16. Haring KA, Lovett DL (1990) A follow-up study of special education graduates. J Spec Educ 23(4): 463-477

17. Kavale KA, Holdnack J, Mostert MP (2003) The feasibility of a responsiveness to intervention approach for the identification of specific learning disability: a psychometric alternative. Paper presented at the National Research Center on Learning Disabilities Responsiveness-to-Intervention Symposium, Kansas City

18. Galico RP, Burns TJ, Grob CS (1988) Emotional and behavioral problems in children with learning disabilities. College-Hill Press/Little, Brown \& Co, Boston

19. Barlow F, Turk J (2001) Adolescents with learning disability and psychiatric illness: two case reports. Clin Child Psychol Psychiatry 6(1):125-135

20. Public Law 94-142 (1975) Individuals with Disabilities Education Act. Retrieved Dec 242008 from http://www.scn.org/ bkk269/94-142.html

21. Reiss S, Peterson RA, Gursky DM, McNally RJ (1986) Anxiety sensitivity, anxiety frequency, and the predictions of fearfulness. Behav Res Ther 24(1):1-8

22. Hoskyn M, Swanson HL (2000) Cognitive processing of low achievers and children with reading disabilities: a selective meta-analytic review of the published literature. Sch Psychol Rev 29:102-119

23. Semrud-Clikeman M (2005) Neurological aspects for evaluating learning disabilities. J Learn Disabil 38(6):563-568

24. Reynolds CR, Richmond RO (1985) Manual for the Revised Children's Manifest Anxiety Scale. Western Psychological Services, Los Angeles

25. Kovacs M (1983) The Children's Depression Inventory: a self-rated depression scale for school-aged youngsters. Unpublished manuscript, University of Pittsburg School of Medicine, Pittsburgh

26. March JS, Parker JD (1999) The Multidimensional Anxiety Scale for Children (MASC). In: Maruish ME (ed) The use of psychological testing for treatment planning and outcome assessment, 2nd edn. Lawrence Eribaum Associates, Mahwah, pp 299-322

27. Dierker JC, Albano AM, Clarke GN, Heimberg RG, Kendall PC, Merikangas KR, Lewinsohn PM, Offord DR, Kessler R, Kupfer DJ (2001) Screening for anxiety and depression in early adolescence. J Am Acad Child Adolesc Psychiatry 40(8):929-936

28. Baldwin JS, Dadds MR (2007) Reliability and validity of parent and child versions of the Multidimensional Anxiety Scale for Children in Community Samples. J Am Acad Child Adolesc Psychiatry 46(2):252-260

29. Grills-Taquechel AE, Ollendick TH, Fisak B (2008) Reexamination of the MASC factor structure and discriminant ability in a mixed clinical outpatient sample. Depress Anxiety 25(11):942-950

30. March JS, Conners C, Arnold G, Epstein J, Parker J, Hinshaw S, Abikoff H, Molina B, Wells K, Newcorn J, Schuck S, Pelham WE, Hoza B (1999) The Multidimensional Anxiety Scale for Children (MASC): confirmatory factor analysis in a pediatric ADHD sample. J Atten Disord 3(85):85-89

31. Yen $\mathrm{C}$, Yang $\mathrm{P}, \mathrm{Wu} \mathrm{Y}, \mathrm{Hsu} \mathrm{F}$, Cheng $\mathrm{C}$ (in press). Factor structure, reliability, and validity of the Taiwanese version of the multidimensional anxiety scale for children. Child Psychiatry Hum Dev. Received March 92010 from http://www.springerlink.com/content/dk853230xh0um1k7/fulltext.pdf

32. Olason DT, Sighvatsson MB, Smari J (2004) Psychometric properties of the Multidimensional Anxiety Scale for Children (MASC) among Icelandic schoolchildren. Scand J Psychol 45:429-436

33. Yao S, Zou T, Zhu X, Abela JRZ, Auerbach RP, Tong X (2006) Reliability and validity of the Chinese version of the Multidimensional Anxiety Scale for Children among Chinese secondary school students. Child Psychiatry Hum Dev 38:1-16

34. Wood JJ, Piacentini JC, Bergman RL, McCracken J, Barrios V (2002) Concurrent validity of the anxiety disorders section of the Anxiety Disorders Interview Schedule for DSM-IV: child and parent version. J Clin Child Adolesc Psychol 31(3):335-342

35. American Psychiatric Association (2000) Diagnostic and statistical manual of mental disorders (Revised 4th edn.). American Psychiatric Association, Washington, DC

36. Christner RW, Stewart JL, Freeman A (eds) (2007) Handbook of cognitive- behavior group therapy with children and adolescents: specific settings and present problems. Routledge/Taylor \& Francis Group, New York

37. Andersson U (2010) Skill development in different components of arithmetic and basic cognitive functions: findings from a 3-year longitudinal study of children with different types of learning difficulties. J Educ Psychol 102(1):115-134

38. Fuchs LS, Fuchs D (2002) Mathematical problem-solving profiles of students with mathematics disabilities with and without comorbid reading disabilities. J Learn Disabil 35:563-573

39. Jensen J, Breiger D (2005) Learning disorders. In: Cheng K, Meyers KM (eds) Child and adolescent psychiatry. Lippincott Williams \& Wilkins, Philadelphia, pp 281-296 
40. Lyon GR, Fletcher JM, Barnes MC (2003) Learning disabilities. In: Mash EJ, Barkley RA (eds) Child psychopathology, 2nd edn. Guilford, New York, pp 520-586

41. Barbosa J, Tannock R, Manassis K (2002) Measuring anxiety: parent-child reporting differences in clinical samples. Depress Anxiety 15:61-65

42. Silverman W, Saavedra L, Pina A (2001) Test-retest reliability of anxiety symptoms and disorders with the Anxiety Disorders Interview Schedule for DSM-IV: child and parent versions. J Am Acad Child Adolesc Psychiatry 40(8):937-944

43. Piers E, Herzberg D (2002) The Piers-Harris children's self-concept scale, 2nd edn. Western Psychological Services, Los Angeles

44. Silverman R, Zigmond N (1983) Self-concept of learning disabled adolescents. J Learn Disabil 16:478482

45. Cooley EJ, Ayres R (1988) Self-concept and success-failure attributions of learning disabled and nonhandicapped students. J Learn Disabil 21:174-178

46. Achenbach TM (1991) Integrative guide for the 1991 CBCL/4-18, YSR, and TRF profiles. University of Vermont, Department of Psychiatry, Burlington

47. Campbell DT, Fiske DW (1959) Convergent and discriminant validation by the multitrait-multimethod matrix. Psychol Bull 56:81-105

48. Cohen J (1988) Statistical power analysis for the behavioral sciences, 2nd edn. Lawrence Erlbaum Associates, New Jersey

49. Hosmer DW, Lemeshow S (2000) Applied logistic regression, 2nd edn. Wiley, New York

50. Engel NA, Rodrique JR, Geffken GR (1994) Parent-child agreement on ratings of anxiety in children. Psychol Rep 75(3 Pt. 1):1251-1260

51. Rubin K, Coplan R, Bowker J (2009) Social withdrawal in childhood. Ann Rev Psychol 60:141-171

52. Kavale KA, Forness SR (1995) The nature of learning disabilities. Lawrence Erlbaum Associates, Mahwah

53. Kavale K, Spaulding L, Beam A (2009) A time to define: making the specific learning disability definition prescribe specific learning disability. Learn Disabil Q 32(1):39-48 